\title{
The palmaris longus muscle: A surface study of the population of North Cyprus
}

\author{
Maryam N ALIYU ${ }^{1}$ (D), Mehtap TIRYAKIOGLU² (D) \\ ${ }^{1}$ Department of Human Anatomy, Faculty of Basic Medical Sciences, Yusuf Maitama Sule University, PMB 3099, Kano, Nigeria. \\ ${ }^{2}$ Department of Anatomy, School of Medicine, Near East University, Nicosia, TRNC Mersin 10, Turkey.
}

Corresponding Author: Mehtap TIRYAKIOGLU

E-mail: mehtap.tiryakioglu@neu.edu.tr

Submitted: 11.01.2021 Accepted: 23.04.2021

\begin{abstract}
Objective: The aim of this research is to determine the frequency of surface anatomical variations of palmaris longus (PL) muscle in the population of North Cyprus and their association with gender, body side, and hand dominance.

Materials and Methods: The presence of PL was determined in 1280 subjects ( 660 females and 620 males) using four testing methods; Schaeffer's test, the Thompson's test, Pushpakumar's test and the Bhattacharya's test. Where the presence of the PL could not be determined by any of these tests, palpation was performed as the final confirmatory test.

Results: The overall frequency of absence was $17.4 \%$. Female subjects showed a higher frequency of absence of $10.6 \%$ compared to males $(6.8 \%)$. The absence was more likely to occur in the non-dominant hand. In those that had the PL, there were 28 (2.6\%) cases of a split tendon and 3 cases $(0.2 \%)$ of a laterally displaced tendon of the PL.

Conclusion: The overall frequency of absence of PL in North Cyprus was $17.4 \%$ and absence is more likely to occur in females, on the left side and in the non-dominant hand. Other variations recorded are the split tendons and laterally displaced tendons.

Keywords: Palmaris longus, Anatomical variation, Agenesis, Forearm, North Cyprus
\end{abstract}

\section{INTRODUCTION}

The palmaris longus (PL) muscle is one of the four superficial muscles on the flexor aspect of the forearm. It originates from the common flexor tendon at the medial epicondyle of humerus and converges into a long and slender tendon that passes anterior to the flexor retinaculum before it becomes flattened to blend with the palmar aponeurosis. It flexes the wrist joint and tenses the palmar aponeurosis [1-3].

The PL has received worldwide attention from researchers, despite the fact that functionally, it is a negligible muscle. It is believed to be functionally more active in mammals that use their upper limbs for mobilization $[4,5]$. It has lost its function in the course of human evolution and is gradually becoming extinct [6-8]. This evolution-induced morphometric change has made the PL one of the most variable muscles in the body [4, 5 , 9]. It may be absent on one or both sides $[3,10]$ or may be reversed, duplicated or digastric [3].

Surgeons consider the tendon of PL as the tendon of choice in reconstructive surgeries, because it is of the right length and diameter, it is easily accessible and its absence does not produce any functional deformity $[4,11]$. It is used by plastic surgeons in treatment of facial paralysis, repairing ptosis, lip augmentation, and in the restoration of lip and chin defects [12-14]. The tendon of PL is also harvested to repair oncologic defects of head and neck and arthritis of the thumb [15].

The variations of PL can cause many clinical syndromes as reported by various researchers. A study reported a clinical case of a bitendinous PL causing median nerve compression during a standard carpal tunnel release [16].

Many textbooks of anatomy show a worldwide prevalence of absence of PL as $10-15 \%[3,17]$ although, prevalence as low as $0.6 \%$ has been recorded in the Korean population [18] and as high as $63.9 \%$ in the Turkish population [19].

However, despite the several studies to determine the prevalence of absence of the PL in various ethnic groups worldwide, there is a dearth of information on the North Cyprus population. To the best of the authors' knowledge, the prevalence of absence of

How to cite this article: Aliyu MN, Tiryakioglu M. The palmaris longus muscle: A surface study of the population of North Cyprus. Marmara Med J 2021; 34(3):267-273. doi: 10.5472/marumj.1013454 
the PL in the North Cyprus population is unknown. Therefore, the aim of this research is to determine the frequency of surface anatomical variations of PL muscle in North Cyprus and their association with gender, body side and hand dominance. The findings will be useful to surgeons working in North Cyprus, especially in the fields of plastic surgery and orthopedics. It will also increase the available data on the PL, thus contributing to the research community.

\section{MATERIALS and METHODS}

The study was done in the Faculty of Medicine, Department of Anatomy, Near East University after approval of the Ethical Board of the Institute of Health Sciences, Near East University (Project Number: 807, Meeting Number: 2019/68, Date of the Ethical Board Meeting: 02/05/2019) and the Ministry of Education, North Cyprus. A written informed consent was sought from each participant before the study was carried out.

The study was conducted in 3 schools within the Nicosia district of North Cyprus; the Turkish High School of Nicosia, the Turkish Education College, and the Near East University. The study was planned as a cross sectional study and the sampling was done sequentially until the target population is reached. The sample size was determined using the population of 300,000 North Cypriots using a confidence interval of $95 \%$ and a margin of error of $3 \%$ and was calculated to be 1,064 .

A total of 1280 participants were assessed for surface variations of the PL. Four testing methods were used, which included the Schaeffer's test, the Thompson's test, Pushpakumar's test and the Bhattacharya's test [20]. Where the PL was not visualized by the 4 methods, palpation was done as the final confirmatory for absence. Presence of other variations of the PL tendon was also assessed. Subjects with hand and wrist deformities, previous injuries or surgeries in the forearm and wrist, less than 10 years age or above 60 years, were excluded from the study.

\section{Statistical Analysis}

The data collected was entered into a Microsoft Excel spreadsheet then exported to SPSS version 20. All statistical analyses were carried out using SPSS. These include frequencies, percentages and chi-square tests. A value of $\mathrm{p}<0.05$ was considered to indicate a statistical significance between variables and the degree of freedom was taken as 1 . The Yates correction was applied in 2 data sets.

\section{RESULTS}

A total of 1,280 subjects were examined out of which 660 were females and 620 were males. PL agenesis was found in 223 cases (17.4\%). 28 cases $(2.6 \%)$ showed a split (bifid) tendon and 3 cases $(0.2 \%)$ presented with a laterally shifted tendon (Figure 1 ). Out of the total, unilateral absence was observed to be 158 (12.3\%), of which right unilateral absence was $40(3.1 \%)$, and left unilateral absence was 118 (9.3\%). The frequency of bilateral absence of PL was observed to be 65 (5.1\%). The distribution of absence based on gender is shown in Figure 2.

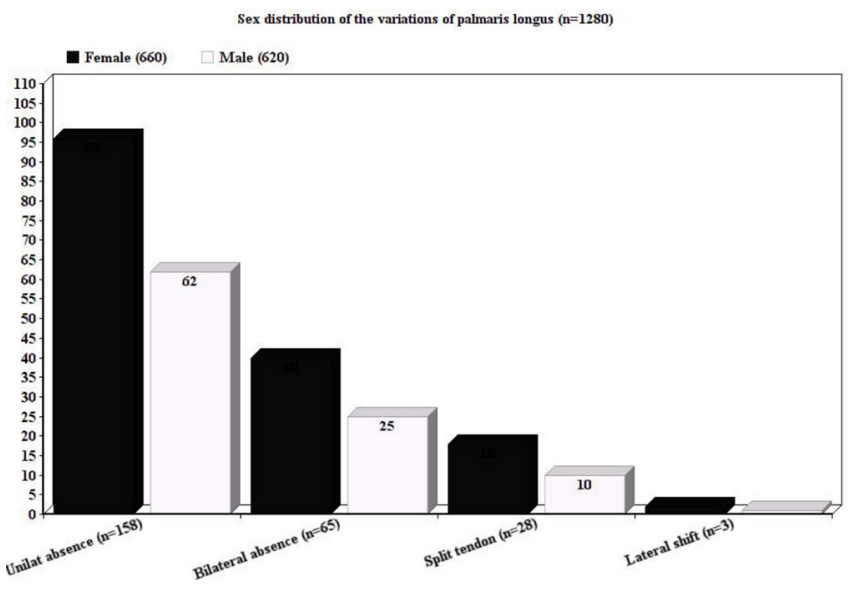

Figure 1. Distribution of variations based on sex

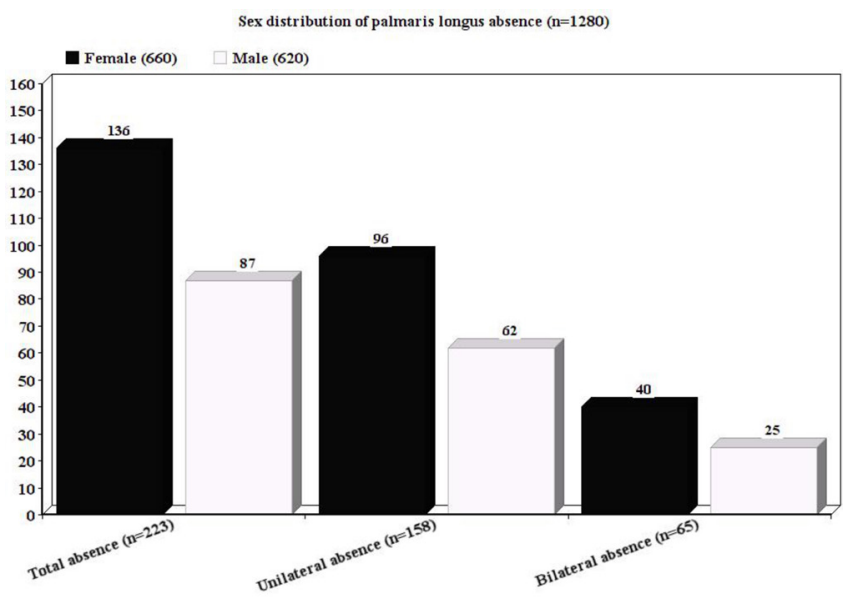

Figure 2. Distribution of PL absence based on sex

The distribution of PL agenesis among the different nationalities and/or regions was found to be 96 (7.5\%) for Cypriots, $86(6.7 \%)$ for Turks, 30 (2.3\%) for Arabs, 4 (0.3\%) for Africans and 7 (0.5\%) for others (Table I).

Table I. Distribution of palmaris longus absence based on nationalities and/or regions (North Cyprus, Nicosia, 2019) $(N=1280)$

\begin{tabular}{|c|c|c|c|c|c|c|c|c|}
\hline & \multirow{2}{*}{\multicolumn{2}{|c|}{$\begin{array}{l}\text { Right } \\
\text { Absence }\end{array}$}} & \multirow{2}{*}{\multicolumn{2}{|c|}{$\begin{array}{l}\text { Left } \\
\text { Absence }\end{array}$}} & \multirow{2}{*}{\multicolumn{2}{|c|}{$\begin{array}{l}\text { Bilateral } \\
\text { Absence }\end{array}$}} & \multirow{2}{*}{\multicolumn{2}{|c|}{ Total }} \\
\hline & & & & & & & & \\
\hline & $\mathrm{n}$ & $\%$ & $\mathrm{n}$ & $\%$ & $\mathrm{n}$ & $\%$ & $\mathrm{n}$ & $\%$ \\
\hline $\begin{array}{l}\text { Cypriots } \\
(\mathrm{n}=633)\end{array}$ & 20 & 20.8 & 43 & 44.8 & 26 & 27.1 & 96 & 100 \\
\hline Turks $(\mathrm{n}=518)$ & 16 & 18.6 & 45 & 52.3 & 32 & 33.3 & 86 & 100 \\
\hline Arabs $(n=66)$ & 2 & 6.7 & 25 & 83.3 & 3 & 10 & 30 & 100 \\
\hline Africans $(n=45)$ & 1 & 25.0 & 1 & 25.0 & 2 & 50 & 4 & 100 \\
\hline Others $(\mathrm{n}=18)$ & 1 & 14.2 & 4 & 57.1 & 2 & 28.6 & 7 & 100 \\
\hline Total & 40 & & 118 & & 65 & & 223 & \\
\hline
\end{tabular}


Unilateral and bilateral absence of PL is shown by Figures 3AB. The presence of a split tendon was observed in 28 subjects (2.6\%); 24 cases occurred on the right, 2 on the left, and 2 bilaterally (Figures 4 A-B).

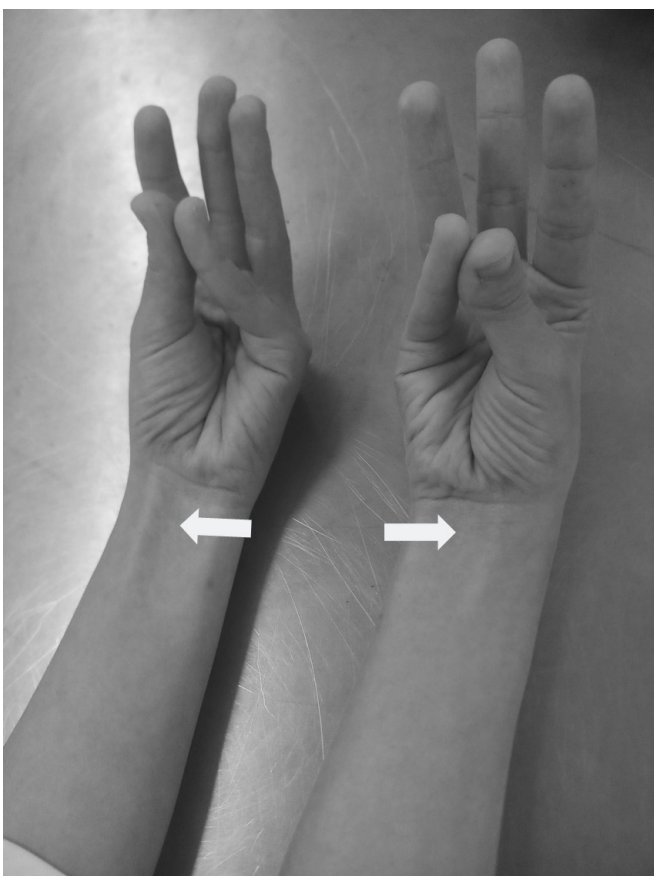

Figure 3A. Bilateral absence of palmaris longus tendon in a $22 y$ old Persian female demonstrated by the Shaeffer's test

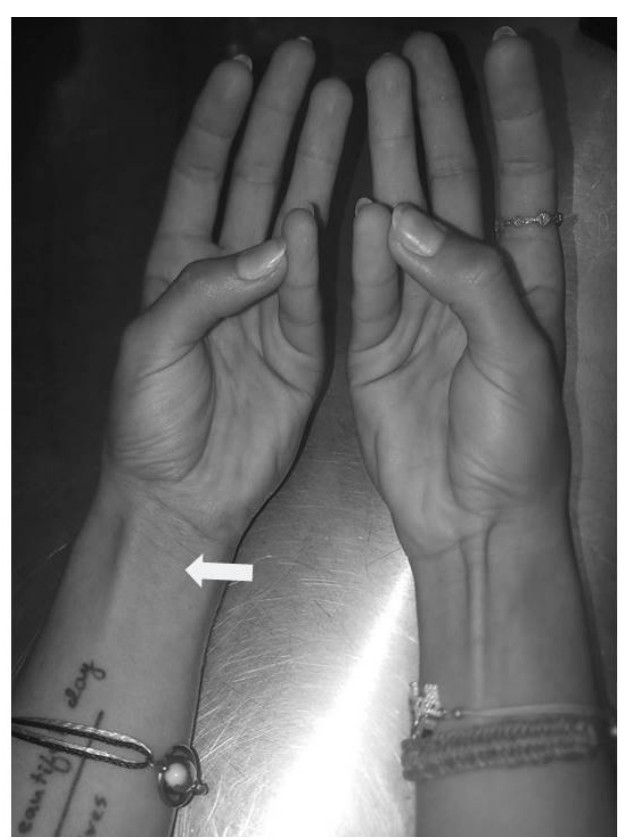

Figure 3B. Unilateral left absence of palmaris longus in a $19 y$ old Cypriot female. The arrow heads point to the tendon of flexor carpi ulnaris which has become more prominent
Out of the total number of cases that presented with PL tendon $(n=1057), 3$ cases $(0.2 \%)$ were observed to have a laterally displaced tendon; 2 cases were females (an African and a Turk) and the other was a Turkish male (Figures 5A-B).

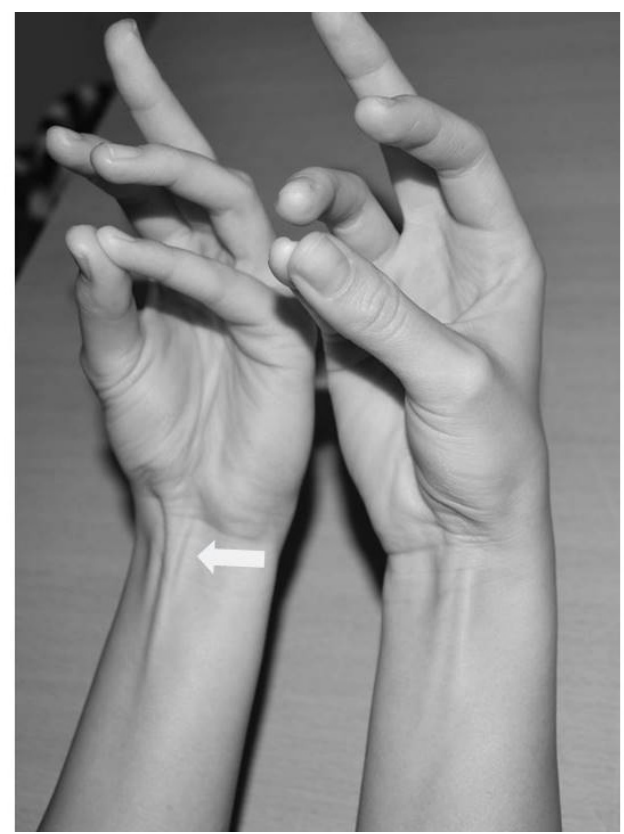

Figure 4A. Left split tendon (shown by arrow head) in a $22 y$ old Russian female visualized by Shaeffer's test

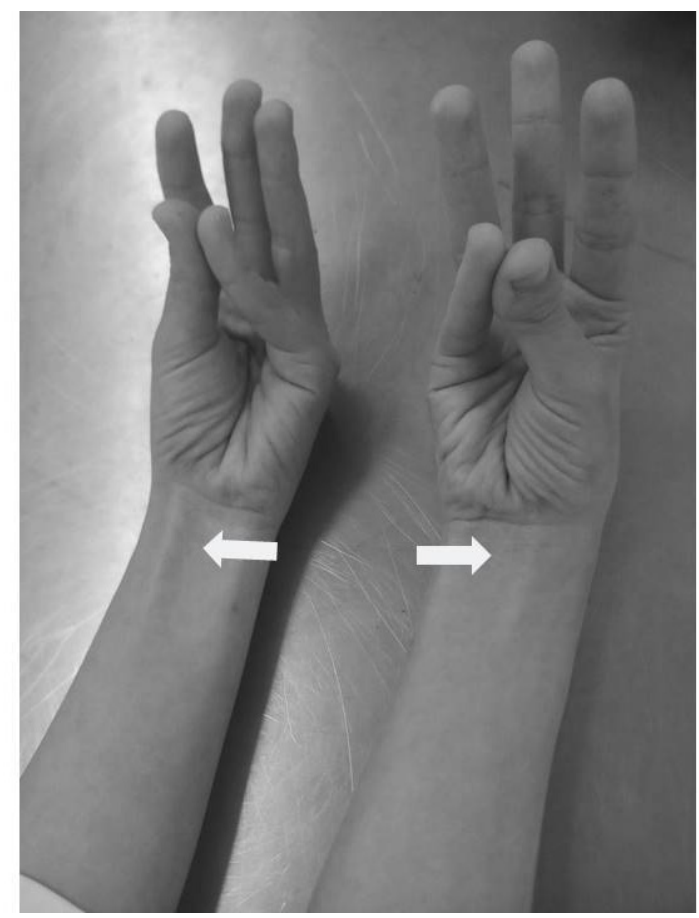

Figure 4B. Right split tendon in a 16y old African female 


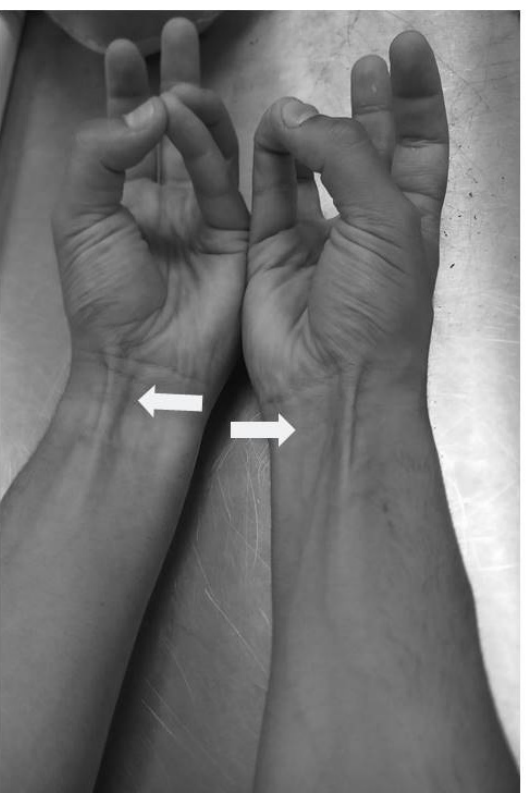

Figure 5A. Laterally displaced tendon of palmaris longus in the right distal forearm of a $24 y$ old Turkish male and split tendon of palmaris longus on the right

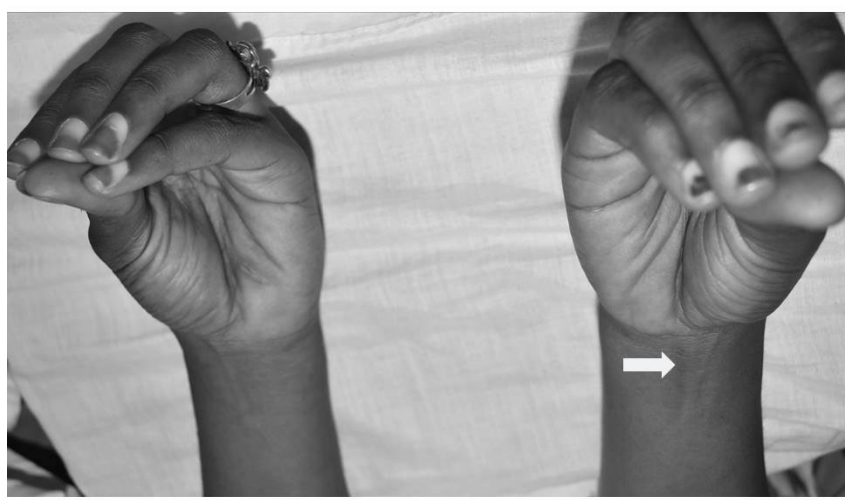

Figure 5B. Laterally displaced left palmaris longus and right split tendon in an African female

The overall difference in PL agenesis between males and females was statistically significant $(\mathrm{p}<.05)$, which implies that females have a higher frequency of absence of PL muscle (Table II).

Table II. Relationship between absence of palmaris longus and gender (North Cyprus, Nicosia, 2019) $(N=1280)$

\begin{tabular}{lccccccc}
\multicolumn{1}{c}{ Gender } & \multicolumn{2}{c}{ Present } & \multicolumn{2}{c}{ Absent } & Total & $\chi^{2}$ & p-value \\
& $\mathrm{n}$ & $\%$ & $\mathrm{n}$ & $\%$ & & & \\
Female & 524 & 79.4 & 136 & 20.6 & 660 & 9.61 & 0.002 \\
Male & 533 & 86.0 & 87 & 14.0 & 620 & & \\
Total & 1057 & & 223 & & 1280 & &
\end{tabular}

While trying to find a correlation between the occurrence of the split tendon and gender, the result was not statistically significant $(\mathrm{p}>.05)$. Although, the frequency of a split tendon was higher in females, the chi-square test was not statistically significant (Table III).

Table III. Correlation between split tendon and gender (North Cyprus, Nicosia, 2019) $(N=1280)$

\begin{tabular}{lcccccc} 
Tendon & \multicolumn{2}{c}{ Normal } & \multicolumn{2}{c}{ Split } & $\chi^{2 *}$ & p-value \\
& $\mathrm{n}$ & $\%$ & $\mathrm{n}$ & $\%$ & & \\
Male & 533 & 98.2 & 10 & 1.8 & 1.39 & 0.238 \\
Female & 524 & 96.7 & 18 & 3.3 & & \\
Total & 1057 & & 28 & & & \\
* Yates correction & & & & & &
\end{tabular}

Concerning laterality or body side, there was also a significant statistical difference ( $\mathrm{p}<.05$ for left side) between the right and left sides, which shows that PL agenesis occurs more frequently on the left side (Table IV).

Table IV. Laterality in palmaris longus muscle absence (North Cyprus, Nicosia, 2019) $(N=1280)$

\begin{tabular}{lccccccc} 
Laterality & \multicolumn{2}{c}{ Present } & \multicolumn{2}{c}{ Absent } & Total & $\chi^{2}$ & $\mathrm{p}$-value \\
\hline Left & $\mathrm{n}$ & $\%$ & $\mathrm{n}$ & $\%$ & & & \\
Right & 1162 & 90.8 & 118 & 9.2 & 1280 & 41.04 & $\mathrm{P}<0.001$ \\
\hline
\end{tabular}

The result of the correlation between body side and occurrence of a split tendon was statistically significant at $\mathrm{p}<.05$, and shows that the split tendon is more likely to occur on the right side as shown in Table V.

Table V. Relationship between body side and split tendon of palmaris longus (North Cyprus, Nicosia, 2019) (N=1280)

\begin{tabular}{lcccccccc} 
& \multicolumn{2}{c}{ Normal } & \multicolumn{2}{c}{ Split tendon } & Total & $\chi 2^{*}$ & p-value \\
& $\mathrm{n}$ & $\%$ & $\mathrm{n}$ & $\%$ & & & \\
Right & 1240 & 98.1 & 24 & 1.9 & 1264 & 13.40 & $\mathrm{p}<0.001$ \\
Left & 1162 & 99.7 & 4 & 0.3 & 1166 & & \\
\hline
\end{tabular}

${ }^{*}$ Yates correction

Out of the 1280 subjects, 1214 were right handed and 66 were left handed. 40 cases showed absence of PL on the right and 118 on the left. Out of the total 223 cases of absence, bilateral absence occurred in 57 right hand dominant subjects and 8 left hand dominant subjects. This is shown in Table VI.

Table VI. Relationship between handedness and frequency of absence of palmaris longus (North Cyprus, Nicosia, 1280) $(N=1280)$

\begin{tabular}{lcccccc} 
& \multicolumn{2}{c}{ Handedness } & \multicolumn{2}{c}{ Absence of PL } & $\chi^{2}$ & p-value \\
& $\mathrm{n}$ & $\%$ & $\mathrm{n}$ & $\%$ & & \\
Right & 1214 & 96.8 & 40 & 3.2 & 609.27 & $\mathrm{P}<0.001$ \\
Left & 66 & 35.9 & 118 & 64.1 & & \\
Total & 1280 & & 158 & & &
\end{tabular}


Left sided unilateral absence occured in 109 right handed subjects and 9 left handed subjects while right sided unilateral absence occurred in 37 right handed subjects and 3 left handed subjects. The relationship between handedness and frequency of absence of PL was statistically significant $(p<.05)$ in that the absence was more likely to occur in the non-dominant hand. The $\mathrm{p}$-value for the left hand was $<.001$ which meant PL agenesis was more likely to occur on the left side in a righthanded individuals.

All the cases of the split tendon occurred in right handed subjects, so a comparison could not be made. There were only 3 cases of a laterally displaced tendon, so no statistical analysis could be made.

\section{DISCUSSION}

The tendon of PL muscle, an anterior forearm flexor muscle, is found at the level of the wrist lying between the tendons of the flexor carpi ulnaris and flexor carpi radialis Various studies have reported many different variations of the tendon of PL, especially its absence [3-5, 20-28]. More studies have been conducted to establish a correlation of the absence of PL to body side, gender and hand dominance [6, 29, 30-32].

In this study, the overall frequency of absence of PL among the North Cyprus population was found to be $17.4 \%(n=223)$ (Figure 1). This value is comparable to the study recorded with a $17.09 \%$ frequency of absence among first year Filipino medical students [15]. A similar study conducted on 500 Indian subjects recorded a similar prevalence of absence of $17.2 \%$ [33]. Another study on an Indian population also reported a similar prevalence of $17.2 \%$ [27]. The value is also similar to the worldwide prevalence of absence of $15 \%$ [17]. A study in Van, Turkey recorded a total prevalence of $15.1 \%$ [7]. Higher prevalence of PL agenesis have been given in Chilean subjects as $21 \%$ [6] while it was $22.8 \%$ in Iran [4], 26.6\% in Turkey [8], 26.7\% in Nigeria [29], 28\% in India [13], and $40.5 \%$ in Saudi Arabia [12]. A study conducted in the Gaziantep population of Turkey reported the highest prevalence as $63.9 \%$ [19]. Many studies have recorded lower prevalence of absence especially in studies conducted in Africa and Asia. In South Africa it was reported as $11.5 \%$ [34]; In Iranian subjects it was reported as $10.2 \%$ prevalence of absence [4], while it was $9.3 \%$ in Malaysia [14]; Yoruba population of Nigeria showed $6.7 \%$ [15]; East Africa as 4.4\% [9]; Korea as 4.1\% [18]; Ghana as $3.8 \%$ [35]; and Zimbabwe as $1.6 \%$ [30].

Out of the total prevalence of absence in this study (17.4\%), a total of $158(12.3 \%)$ cases exhibited unilateral absence while 65 (5.1\%) cases showed bilateral absence. In the unilateral cases, 40 subjects (3.1\%) exhibited unilaterality on the right, and 118 $(9.3 \%)$ showed left unilateral absence (Figure 2). From this study, it was inferred that there is a higher frequency of unilateral absence of the PL tendon. This was supported by a report with the total prevalence of absence of $21 \%, 11 \%$ were unilateral and $9 \%$ bilateral [6]. In another study, it is also recorded with a $6.4 \%$ unilateral absence and $2.9 \%$ bilateral absence, out of the total $8.3 \%$ [14]. The study by Yong et al., also reported that left sided absence was more common [32]. Also, the East African study reported that out of the total $4.4 \%$ cases of absence, $3.3 \%$ were unilateral and $1.1 \%$ was bilateral [9]. The results of the current study were in contrast to the results of a study that reported a higher incidence of bilateral absence $(6.7 \%$ out of the total $10.2 \%$ ) [4]. Some other studies showed no significant difference between unilateral and bilateral cases; one study reported that of the $26.7 \%$ cases of absence, $13 \%$ were unilateral and $13.7 \%$ were bilateral [29] while another one reported no statistically significant difference in terms of sidedness [15]. Similarly, one of the studies reported that the development and the prevalence of agenesis of the PL in the fetal period had no significant differences based on sidedness, although, bilateral absence was significantly higher $(62.2 \%)$ when compared to unilateral prevalence (15\%) [36]. In the current study, the unilateral cases were $3.1 \%$ on the right and $9.3 \%$ on the left (Table IV). This contrasted with the study that showed a higher distribution on the right side $(10.2 \%)$ compared to the $5.9 \%$ on the left [4]. In comparison, a study showed equal distribution on both right and left sides (5.6\%) [29], same as another study which showed $1.4 \%$ prevalence of absence on both sides [35]. One study showed a slightly higher prevalence on the left (6\%) compared to the $5 \%$ on the right side [6].

Studies have tried to correlate the frequency of absence of the PL with gender. The report of a study showed a higher frequency of absence in females (15.1\%) compared to males (11.2); of these cases, $9.0 \%$ cases were on the left side [6]. The current study also showed a higher frequency of absence in females (10.6\%) compared to the males $(6.8 \%)$. The relationship between gender and absence of the PL was statistically significant $(\mathrm{p}<.05)$ (Table II). The total frequency of absence on the right side was $3.1 \%$ while on the left, it was $9.2 \%$; 19 of the female subjects $(1.9 \%)$ had unilateral absence on the right and 77 (6.0\%) had unilateral absence on the left; while the male frequency of absence was $1.6 \%$ on the right and $3.2 \%$ on the left. In this study, the p-value for the left was statistically significant $(\mathrm{p}<.05)$ (Table IV). This finding was also supported by the study which reported $37.5 \%$ absence in females and $27.9 \%$ in males, with a p-value for left hand being 0.017 [37]. While, one study also reported a higher frequency of absence in females and on the left [29], another study reported males to have $16 \%$ unilateral agenesis and $4 \%$ bilateral agenesis while females had 29\% unilateral agenesis and $14 \%$ bilateral agenesis [18]. In contrast, another study reported a higher frequency of absence in males (4.7\%) compared to $3.3 \%$ in females, with no statistically significant difference as to laterality. A study conducted in Malaysia reported a higher frequency in females ( $11.5 \%$ compared to $7.1 \%$ in males) but there was no statistically significant difference in laterality as the $\mathrm{p}$-value for the left was 0.105 [14]. This finding was in contrast to the findings of studies that showed no statistically significant difference in genders $[4,34]$. The study of frequency in Chilean subjects showed that the PL was most frequently absent on the left side and in women, but the statistical test was not significant [6].

The current study recorded a bilateral absence of PL in 57 (4.5\%) right hand dominant subjects and $8(0.6 \%)$ in left hand dominant subjects. 109 cases (8.5\%) had unilateral absence on the left side 
while 9 cases $(0.7 \%)$ had unilateral absence on the left side. On the other hand, 37 right-handed subjects $(2.9 \%)$ had unilateral absence on the right; while $3(0.2 \%)$ left-handed subjects had absence on the right. The difference between right and left hand dominance and frequency of absence of PL was statistically significant ( $\mathrm{p}$-value is $<.001$ at $\mathrm{p}<.05$ ) for the non-dominant hand, which showed that absence of PL was more likely to occur in the non-dominant hand (Table VI). This finding was supported by a study concluded that right-sided absence was more common in left-handed persons while left-sided absence was more common in the right-handed persons [38]. Kigera and Mukwaya reported similar findings that PL agenesis was more likely to occur in a non-dominant hand [9]. Another study reported no significant difference in terms of gender, body side and handedness, but concluded that the absence of PL tendon was more likely to occur in the non-dominant hand [35]. Another study however, reported a contradicting result that there was a significant relationship between PL agenesis and left hand dominance, that those with PL agenesis were 3.7 times more likely to be left-hand dominant and left handed people were 3.7 times more likely to have PL agenesis [4]. No other study has reported similar findings. Kyung et al., concluded that there was no relationship between hand dominance and PL absence [18].

This study also documented 28 cases $(2.5 \%)$ of the total number of those that were positive for the PL tendon of a split (bifid) tendon of PL, of which $10(0.9 \%)$ cases occurred in males and 17 $(1.6 \%)$ in females. Although, the frequency of a split tendon was higher in females, the chi-square test was 1.43 and $\mathrm{p}$-value was .23 which was $\mathrm{p}>.05$ (Table III); this implied that the difference in gender was not statistically significant. In the cases with split tendon, 24 cases occurred on the right, 1 bilaterally and 2 on the left side. The chi-square test was 14.86 and $\mathrm{p}$ - value was < 0.001 , which was statistically significant at $\mathrm{p}<.05$, which means that the split tendon is more likely to occur on the right side (Table V). However, no similar studies were found to compare and contrast this result. In the literature, there is a case report of 2 cases of an anomalous V-shaped bifid tendon of PL [39].

There were 3 cases $(0.2 \%)$ of a laterally displaced tendon of PL on the right forearms of a Turkish male (Figure 3A), Turkish female, and the left forearm of an African female (Picture 3b). Another study reported a lateral shift in the tendon of PL in $1.1 \%$ of subjects [30].

The frequency of absence in the ethnic groups of North Cyprus could not be compared as there were no similar studies in the region to compare. No other abnormalities have been observed in this study.

In summary, the goals of this research were to establish the frequency of surface anatomical variations in the different races in North Cyprus and to correlate these variations with gender, body side and hand dominance. All these have been established in this research. The frequency of absence was $17.4 \%$, frequency of split tendon was $2.5 \%$ and lateral tendon was $0.2 \%$. There was a significant statistical correlation between these variations, gender, body side and hand dominance. From this study, it can be concluded that PL agenesis is more likely to occur in females and on the left side, and in the non-dominant hand.

\section{Compliance with Ethical Standards}

Ethical Approval: This study was approved by the Ethics Committee of the Institute of Health Sciences, Near East University (Project Number: 807, Meeting Number: 2019/68, Date of the Ethical Board Meeting: 02/05/2019) and the Ministry of Education, North Cyprus. A written informed consent was sought from each participant before the study was carried out.

Funding: The authors have no relevant financial information to disclose.

Conflict of interest: The authors declare no conflict of interest.

Authors' Contrubition: M.N.A., M.T.: Idea/ Concept. M.N.A.:: Design. M.T.:. Control/Supervision. N.N.A.:Data Collection and processing. M.N.A., M.T.: Analysis. M.N.A., M.T.: Literature review. M.T.: Critical Review. Both authors approved the final version of the article.

\section{REFERENCES}

[1] Moore KL, Dalley AF, Agur AMR. Clinically Oriented Anatomy. Philadelphia: Wolters Kluwer Lippincott Williams and Wilkins, 2014: 744-750.

[2] Snell RS. Clinical anatomy by regions. Philadelphia: Wolters Kluwer Lippincott Williams and Wilkins, 2018: 382-98.

[3] Standring S, Anand N, Birch R, Collins P, Crossman AR, Gleeson M, Wigley CB. Gray's Anatomy. The Anatomical Basis of Clinical Practice. New York: Elsevier, 2016: 848-61.

[4] Lahiji FA, Ashoori K, Dahmardehei M. Prevalence of palmaris longus agenesis in a hospital in Iran. Arch Iran Med 2013; 16 : 187-8.

[5] Pai MM, Prabhu LV, Nayak SR, et al. The palmaris longus muscle: its anatomic variations and functional morphology. Rom J Morphol Embryol 2008; 49: 215-217.

[6] Alves N, Ramirez D, Deana NF. Study of frequency of palmaris longus in Chilean subjects. Int J Morphol 2011; 29: 485-9.

[7] Hiz Ö, Ediz L, Ceylan MF, Gezici E, Gulcu E, Erden M. Prevalence of the absence of palmaris longus muscle assessed by a new examination (Hiz-Ediz Test) in the population residing in the area of Van, Turkey. J Clin Exp Invest 2011; 2:254-9.

[8] Kose O, Adanir O, Cirpar M, Kurklu M, Komurcu M. The prevalence of absence of the palmaris longus: a study in Turkish population. Arch Orthop Trauma Surg 2009;129: 60911.

[9] Kigera JWM, Mukwaya S. Frequency of agenesis of palmaris longus through clinical examination - An East African study. PLoS One 2011; 6: e28997. doi: 0.1371/journal.pone.0028997

[10] Natsis K, Levva S, Totlis T, Anastasopoulos N, Paraskevas G. Three-headed reversed palmaris longus muscle and its clinical significance. Ann Anat 2007; 189: 97-101. 
[11] Lamichhane PS, Sharma K, Lamichhane N. Study on palmaris longus muscle tendon agenesis among first year Filipino medical students. J Gandaki Med Coll Nepal 2017; 10 :17-20.

[12] Alabbad AA, Marwah HA, Marwah S, Alahmad SA. The frequency of palmaris longus absence among female students in King Faisal University in Al-Ahsa, Saudi Aradia. Egyptian J of Health Med 2018; 70: 1959-62. doi: 10.12816/0044850

[13] Devi SK, Bhanu PS, John SP. Incidence of agenesis of palmaris longus in the Andhra population of India. Indian J Plast Surg 2011; 44:134-8. doi: 10.4103/0970-0358.81448

[14] Roohi SA, Choon-Sian L, Shalimar A, Tan GH, Naicker AS, Rehab MM. A study on the absence of palmaris longus in a multi-racial population. Malaysian Orthop J 2007, 1 : 26-8.

[15] Mbaka GO and Ejiwunmi AB. Prevalence of Palmaris longus absence - a study in the Yoruba population. Ulster Med J 2001; 78: $22-4$.

[16] Lorenzo JS, Canada M, Diaz L, Sarasua G. Compression of the median nerve by an anomalous palmaris longus tendon: A case report. J Hand Surg 1996; 21A: 858-60. doi: 10.1016/ s0363-5023(96)80204-8.

[17] Drake RL, Vogl AW, Mitchel AWM. Gray's Anatomy for students. Philadelphia: Churchill Livingstone Elsevier, 2015: 776-81.

[18] Kyung DS, Lee JH, Choi IJ, Kim DK. Different frequency of the absence of the palmaris longus according to assessment methods in a Korean Population. Anat Cell Biol 2012; 45:53-6. doi: 10.5115/acb.2012.45.1.53

[19] Ceyhan O, Mavt A. Distribution of agenesis of palmaris longus in 12 to 18 years old age groups. Indian J Med Sci 1997; 51: 156-160.

[20] Kigera JWM and Mukwaya S. Clinical assessment of the palmaris longus - accuracy of common tests. The Annals of African Surgery 2012; $9: 104-7$.

[21] Alzahrani MS, Almalki MA, Al-Thunayan TA, Almohawis AH, Al Turki AT, Umedani L. Absence of palmaris longus and flexor digitorum superficialis muscles in young Saudi population. Anatomy Research International vol. 2017; Article ID: 5342497, 6 pages, 2017. doi: 10.1155/2017/5342497

[22] Arquez HF. Morphological study of palmaris longus muscle. International Archive of Medicine: Human Anatomy Section 2017; 10:1-6.

[23] Ashby BS. Hypertrophy of the Palmaris longus muscle. J Bone Joint Surg Br 1964; 46 : 230-2.

[24] Barkats N. Hypertrophy of palmaris longus muscle, a rare anatomic aberration. Folia Morphol 2015; 74: 262-4.

[25] Cerda A, Del Sol M. Morphology and morphometry of the tendons of palmaris longus and radial carpal extensor muscles in humans. Int J Morphol 2016; 34 : 1515-21.
[26] Das S. Farihah S. Palmaris longus muscle: presence or absence, does it matter? Med Health 2013, 8: 1-2.

[27] Kapoor SK, Tiwari A, Kumar A, Bhatia R, Tantuway V, Kapoor $\mathrm{S}$. Clinical relevance of palmaris longus agenesis: Common anatomical aberration. Anat Sci Int 2008; 83: 45-8.

[28] Thompson NW, Mockford BJ, Cran GW. Absence of the palmaris longus muscle: a population study. Ulster Med J 2011; $70: 22-4$.

[29] Adejuwon SA, Salawu OT, Ajibola B. Agenesis of palmaris longus muscle in selected population of school childres in Nigera. Int J Morphol 2012; 30: 1593-6.

[30] Gangata $H$. The clinical surface anomalies of the palmaris longus muscle in the Black African population of Zimbabwe and a proposed new testing technique. Clin Anat 2009; 22: 230-5. doi: 10.1002/ca.20751

[31] Sebastin SJ, Lim AYT, Wong H-B. Clinical assessment of absence of the Palmaris Longus and its association with other anatomical anomalies - a Chinese population study. Ann Acad Med Singapore 2006; 35: 249-53.

[32] Yong MW, Yusof N, Rampal L, Arumugam M. Prevalence of absence of palmaris longus and its association with gender, hand dominance and absence of FDS tendon to little finger among Malay population. J Hand Surg Asian Pac 2017; 22: 484-9. doi: 10.1142/S021.881.041750054X.

[33] Sebastin SJ, Lim AY, Bee WH, Wong TC, Methil BV. Does the absence of the palmaris longus affect grip and pinch strength? J Hand Surg Br 2005; 30: 406-8.

[34] Ndou R, Ramirez D, Deana NF. Study of frequency of absence of palmaris longus in a South African population of mixed race. Clin Anat 2010; 23:437-42.

[35] Abledu JK, Offei EB. Prevalence of agenesis of palmaris longus and its association with gender, body side, handedness and other anomalies of the forearm in a student population in Ghana. Rawal Medical J 2014; 39: 203-207.

[36] Yammine K, Erić M, Assi C. Variations and morphometrics of palmaris longus in fetuses: a meta-analysis of cadaveric studies. Surg Radiol Anat 2020; 42: 281-287. doi: 10.1007/ s00276.019.02391-9

[37] Cetin A, Gene M, Sevil CY, Coban CY. Prevalence of the palmaris longus muscle and its relationship with grip and pinch strength: a study in a Turkish pediatric population. Hand 2013; 8: 215 - 20.

[38] Eric M, Koprivcic I, Vucinic N, et al. Prevalence of the palmaris longus in relation to the hand dominance. Surg Radiol Anat 2011; 33: 481-4.

[39] Alshalam AA, Mular P, Jawad K. Anomalous V-shape palmaris longus tendon: Two cases. J Med Cases 2010; 1: 68-70. doi: https://doi.org/10.4021/jmc114e 